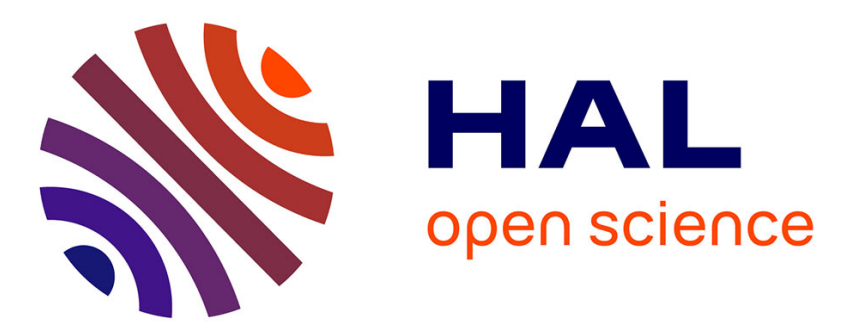

\title{
Evaluation of a natural resin-based new material (Shellac F) as a potential desensitizing agent
}

Bao-Tram Hoang-Dao, Hung Hoang-Tu, Lam Tran-Hung, Jean Camps, Gilles

Koubi, Imad About

\section{- To cite this version:}

Bao-Tram Hoang-Dao, Hung Hoang-Tu, Lam Tran-Hung, Jean Camps, Gilles Koubi, et al.. Evaluation of a natural resin-based new material (Shellac F) as a potential desensitizing agent. Dental Materials, 2008, 24 (7), pp.1001-1007. 10.1016/j.dental.2007.11.014 . hal-03552167

\section{HAL Id: hal-03552167 https://hal.science/hal-03552167}

Submitted on 2 Feb 2022

HAL is a multi-disciplinary open access archive for the deposit and dissemination of scientific research documents, whether they are published or not. The documents may come from teaching and research institutions in France or abroad, or from public or private research centers.
L'archive ouverte pluridisciplinaire HAL, est destinée au dépôt et à la diffusion de documents scientifiques de niveau recherche, publiés ou non, émanant des établissements d'enseignement et de recherche français ou étrangers, des laboratoires publics ou privés. 


\title{
Evaluation of a natural resin-based new material (Shellac F) as a potential desensitizing agent
}

\author{
Bao-Tram Hoang-Dao ${ }^{a, b}$, Hung Hoang-Tu ${ }^{b}$, Lam Tran-Hung ${ }^{a}$, Jean Camps ${ }^{a}$, \\ Gilles Koubi ${ }^{a}$, Imad About ${ }^{a, *}$ \\ a Laboratoire IMEB, Faculté d'Odontologie, Université de la Méditerranée, 27 Bd Jean Moulin, \\ 13355 Marseille, Cedex 05, Marseille, France \\ ${ }^{\mathrm{b}}$ Faculty of Odonto-Stomatology, University of Medicine and Pharmacy, HCM City, Viet Nam
}

\begin{abstract}
A B S T R A C T
Objectives. To evaluate the cytotoxicity of Shellac F, a new fluoride varnish, and its effects on human dentin hydraulic conductance.

Methods. Shellac F was compared to another fluoride varnish (Duraphat ${ }^{\circledR}$ ) and a fluoride containing desensitizing agent (Isodan ${ }^{\circledR}$ ). The cytotoxicity test was performed on human gingival fibroblasts and through dentin slice on human pulp fibroblasts. The hydraulic conductance (Lp) was recorded by fluid filtration with a Flodec device under a constant pressure $\left(15 \mathrm{~cm} \mathrm{H}_{2} \mathrm{O}\right)$. The treated surface of the dentin disks and their sections were also investigated with SEM.

Results. The cytotoxicity test on gingival fibroblasts revealed that Duraphat ${ }^{\circledR}$ was the least cytotoxic material, followed by Shellac F then Isodan ${ }^{\circledR}$. With dentin slice interposition, a lower level of cytotoxicity was obtained. All of them showed a lower cytotoxicity decreasing on further dilutions $(p<0.001)$. The measurement of hydraulic conductance showed that all materials resulted in a significant decrease in dentin permeability after $24 \mathrm{~h}$ comprising between 60 and $76 \%$, but there was no statistically significant difference among the materials. This decrease was still over $50 \%$ of the initial values after 7 days for all three materials. SEM investigation showed dentin tubules covered with a thick layer of Shellac F or Duraphat ${ }^{\circledR}$ whilst no material was observed on dentin surfaces treated with Isodan ${ }^{\circledR}$.

Significance. Shellac F showed an adequate cellular compatibility and a significant effect on human dentin hydraulic conductance. This indicates that the new material is safe and seems tobeeffective as a potentialdesensitizingagent.
\end{abstract}

\section{Introduction}

Dentin hypersensitivity is a common pathology found in the adult population with a prevalence ranging from 4 to $74 \%$ [1] The presence of tubules in dentin makes the tissue permeable, especially when the outer protective layer of enamel or cementum is removed [2]. The most widely accepted mech- anism of dentin hypersensitivity is the hydrodynamic theory proposed by Brännström, whereby outward fluid flow within dentinal tubules is triggered by thermal, tactile or chemical stimuli near the exposed surface of the tubules [3]. It has been demonstrated that patients with dentin sensitivity have large open dentin tubules on the outer surface of the dentin [4-8] Although a wide variety of factors may contribute to 
the exposure of dentinal tubules, $[9,10]$ current desensitizing treatments tend to concentrate on two approaches: to occlude the tubules and to block neural transmission [2].

Professional treatments used to produce tubule occlusion usually involve resins, varnishes, dentin bonding agents or restorative materials. In most cases a macroscopic coating is apparent providing evidence that tubule occlusion has been achieved [9]. Sodium fluoride is one of the most commonly used desensitizers for dentin hypersensitivity with or without iontophoresis [11]. It has been suggested that sodium fluoride decreases sensitivity by occluding the dentin tubules through crystallization, and reducing the fluid flow to the pulp [12].

However, there is enough space to improve the desensitizing agents because they suffer from some limitations. First, many topical desensitizing agents do not adhere to the dentin surface, thus limiting their efficiency over time [10]. Some toothpastes, specially designed for dentin hypersensitivity treatment, have a low abrasion coefficient [13]. Nevertheless, neither the crystals nor the resin polymer deposited onto the dentin surface can withstand the abrasive effects of toothpastes [14]. This results in a loss of treatment efficiency over time. Second, no resinous monomer is biologically inert. Although remaining dentin thickness, which is one of the most important factors that affects dentin permeability, serves as an excellent barrier to both pathological and iatrogenic insults, [15] monomers may diffuse through dentin and have pulpal consequences. [16] In addition, the allergic phenomena due to resins are more and more frequent [17]. Third, few desensitizing agents release fluoride that may contribute to caries prevention when the dental care procedures are not easily applicable. For example, this is the case of disabled patients who cannot brush their teeth correctly.

Shellac is a natural polymer of animal origin secreted by the insect Laccifer Lacca Kerr, which grows on some specific types of trees in China, India, Thailand and Viet Nam. It is composed of hard resin and soft resin of polyester and single ester with polyhydroxypolybasic acids such as aleuritic acid, jalaric acid, and laccijalaric acid. It is soluble in alcohol and alkaline solutions but insoluble in water and possesses a very low water and acid permeability [18]. Because of its natural origin, shellac is an acceptable enteric coating material for phytopharmaceuticals and food additives, where synthetic polymers do not fit into the product image [19]. Due to its protective properties by forming a superficial protective film, it is widely used in the food industry, paint industry, and to a less extent in the pharmaceutical industry. Shellac has been used for sealing, glossing and entercoating of pharmaceutical products [20]. It was also traditionally used as a dental lac in many Pacific countries. In the last few decades, several primary clinical trials have been conducted and published in national reviews in
Viet Nam suggesting the efficiency of this resin as a professional dental product in dental caries prevention and dentin hypersensitivity management. Shellac F, an experimental natural resin-based fluoride varnish, was designed for dentin hypersensitivity treatment and dental caries prevention. It is mainly composed of shellac and enriched with $5 \% \mathrm{NaF}$. The product was officially developed in 1997 (Faculty of OdontoStomatology, University of Medicine and Pharmacy with the collaboration of the Department of Chemistry, University of Polytechnic, HCM city, Viet Nam) [21].

The objective of this study was to evaluate the cytotoxicity of Shellac F and its effects on hydraulic conductance of human dentin. It was hypothesized that this new material might be potentially used as a desensitizing agent.

\section{Materials and methods}

\subsection{Materials}

The experimental Shellac F was compared to:

- Duraphat ${ }^{\circledR}$ (Colgate Palmolive Co., New York, NY, USA), another fluoride-containing lac designed for dentin hypersensitivity treatment and dental caries prevention.

- Isodan ${ }^{\circledR}$ (Septodont, St. Maure les Fossés, France), a fluoride containing desensitizing agent (Table 1).

\subsection{Cytotoxicity study}

All materials used for culture media preparation were purchased from Gibco BRL (Life Technologies Inc., Grand Island, NY, USA), unless otherwise specified. Minimum essential medium (MEM) supplemented with 10\% fetal bovine serum, $100 \mathrm{UI} / \mathrm{ml}$ penicillin, $100 \mu \mathrm{g} / \mathrm{ml}$ streptomycin (Biowhittaker, Gagny, France) was used.

The cytotoxicity of the three materials was evaluated using the MTT test. This was performed under two conditions:

- on human gingival fibroblasts after direct contact between the materials and the culture medium

- and on human pulp fibroblasts with dentin slice interposition between the materials and the culture medium.

Human gingival fibroblasts and human pulp fibroblasts were derived from healthy subjects in compliance with French legislation (informed patients' and parents' consent, and Institutional Review Board approval of the protocol used). Gingival fibroblasts were isolated from explants of normal gingival tissues attached to the extracted third molars and prepared

Table 1 - Composition of three materials used in the study

Shellac F

Duraphat ${ }^{\circledR}$

Isodan $^{\circledR}$
Sodium fluoride (5\%), shellac, modified epoxy resin, acetone and silica

Sodium fluoride (5\%), ethanol, white bee wax (E901), gum lac (E904), colophane, mastic, saccharine (E954) and frasberry essence

Potassium nitrate, sodium fluoride, HEMA and excipients 
according to the method of Uehara et al. [22]. Pulp fibroblasts were prepared from freshly extracted immature third molars of 16-year-old adolescents as described previously [23]. The cells were incubated at $37^{\circ} \mathrm{C}$ in a $95 \%$ air plus $5 \% \mathrm{CO}_{2}$ atmosphere with $100 \%$ relative humidity and used until 8 passages. The medium was changed every day. For the experiment, the cells were plated at 40,000 cells $\mathrm{cm}^{-2}$ in 96 -well plates then placed into an incubator for $24 \mathrm{~h}$ prior to use.

\subsection{Direct contact between the materials and the culture medium on human gingival fibroblasts}

According to ISO standards $0.1 \mathrm{~g}$ of each material was diluted in $1 \mathrm{ml}$ of culture medium and stored for $24 \mathrm{~h}$ at $37^{\circ} \mathrm{C}$. Serial dilutions of these three media $(1: 1,1: 2,1: 10$ and 1:100) were used to replace the medium used to cultivate the gingival fibroblasts for $24 \mathrm{~h}$, before performing the MTT assay.

\subsection{Dentin slice interposition between the materials and the culture medium}

Human third molars stored at $4{ }^{\circ} \mathrm{C}$ in $1 \%$ phosphate buffered saline (PBS) containing $200 \mathrm{UI} / \mathrm{ml}$ penicillin, $200 \mu \mathrm{g} / \mathrm{ml}$ streptomycin (Biowhittaker, Gagny, France) within 3 months were used to prepare dentin slices $(0.5 \pm 0.05 \mathrm{~mm}$-thick) with a low speed diamond saw (Isomet, Buehler Ltd., Lake Bluff IL, USA) and water coolant. They were then dipped into EDTA $14 \%$ for $2 \mathrm{~min}$ to remove the smear layer created by the saw, from both surfaces, and rinsed under tap water for $5 \mathrm{~min}$. To create a constant dentin surface area, the coronal side of dentin slice was attached with a non-cytotoxic cyanoacrylate glue to a Plexiglas ring ( $1 \mathrm{~cm}$ thick, $2 \mathrm{~cm}$ in diameter) with a hole of $0.5 \mathrm{~cm}$ in its center. This standardized the contact dentin surface area to expose $19.62 \mathrm{~mm}^{2}$ of dentin. The test material was applied on the coronal side of the dentin slice and left open to the atmosphere. The pulpal side of the dentin slice was in contact with the medium in the chamber called the receiving medium. A pulsatile pressure $\left(12-18 \mathrm{~cm} \mathrm{H}_{2} \mathrm{O}\right.$ ) was applied to simulate the pulsatile pulpal pressure in vivo. After $24 \mathrm{~h}$, the receiving medium was collected and serial dilutions called test media $(1: 1,1: 2,1: 10$ and 1:100) were used to culture the human pulp fibroblast in the prepared 96-well plates. The 96-well plates were then placed into an incubator for $24 \mathrm{~h}$.

\subsection{MTT assay}

A succinyl dehydrogenase assay (MTT) then was performed to evaluate the respiratory function of the fibroblasts cultivated with the test media containing the dilutions. The test media were removed and immediately replaced with $100 \mu \mathrm{l}$ per well of a $0.5 \mathrm{mg} / \mathrm{ml}$ solution of 3-(4,5-dimethylthiazol-2yl)-2,(-diphenyl tetrazolium bromide $\left.{ }^{n}\right)$ in culture media. After incubation for $2 \mathrm{~h}$ at $37^{\circ} \mathrm{C}$, the supernatant was discarded, and the formazan crystals were solubilized with $100 \mu \mathrm{l}$ per well of dimethylsulfoxide $\left(\mathrm{DMSO}^{n}\right)$. The absorbance of each 96-well plate was determined using an automatic microplate spectrophotometer (E 960, Bioblock, Strasbourg, France) at $550 \mathrm{~nm}$. The absorbance of the wells containing the media with the same dilution in each plate was averaged as a single mea- surement and calculated against that of the control media to determine the toxicity level of the product.

\subsubsection{Statistical analysis}

All experiments were done in triplicate. A two-way analysis of variance (ANOVA) (way 1: dilution and way 2: material) was applied to compare the cytotoxicity of the three desensitizing agents at different dilutions. The ANOVA was followed by a Duncan test to statistically differentiate the three materials. The significance level was set at $5 \%$.

\subsection{Effects on hydraulic conductance}

Dentin slices were prepared from 60 third molars and attached to the Plexiglas ring with the same protocol as described in the cytotoxicity test ( $n=20$ per material). The coronal side of the dentin slice was covered with distilled water and was left open to the atmosphere. The part in contact with the pulpal side was connected to a $0.5 \mathrm{~mm}$-diameter tube. This tube was itself connected to a horizontal capillary and the whole system was filled with distilled water under a hydrostatic pressure of $15 \mathrm{~cm}$ $\mathrm{H}_{2} \mathrm{O}(1.47 \mathrm{kPa})$. A small air bubble in the tube took the role of indicator of fluid movement. The principle of this device is the light-sensitive photodiode with an infrared light beam passing through the edge of the bubble. Since the bubble moved due to fluid displacement through the dentin slice, the diodeenergized step-motor also changed a linear resistance, which provided input to a computer (Flodec ${ }^{\mathrm{e}}$, De Marco Engineering, Geneva, Switzerland). The displacement of the air bubble was measured with an accuracy $5 \mu \mathrm{m}$ for $15 \mathrm{~min}$. Before each series of measurements, a control test was done by replacing the dentin slice with a resin slice to insure that there was no leak or fluid movement anywhere within the device in the absence of dentin slice.

The test material was applied on the coronal side of the dentin slice according to the manufacturer's instruction. The hydraulic conductance (Lp) of each specimen was measured before and after the application (after $24 \mathrm{~h}$, then after 7 days). All specimens were conserved separately in PBS at $37^{\circ} \mathrm{C}$ after each measurement.

\subsubsection{Statistical analysis}

The post-treatment values were expressed as a percentage of the pretreatment values, allowing each dentin slice to serve as its own control. A two-way ANOVA (way 1: time and way 2: material) was not possible because of interactions between both parameters. Two one-way analyses of variance, one for the $24 \mathrm{~h}$ results and another for the 7 days results, followed by a Duncan test, were performed was to compare the effects of the three materials. The significance level was set at $5 \%$.

\subsection{SEM examination}

Twelve additional dentin slices were prepared under the same conditions for scanning electron microscopic examination at $24 \mathrm{~h}$ and 7 days after material applications $(n=4$ per material). The specimens were conserved in PBS at $37^{\circ} \mathrm{C}$ between material application and examination.

For each SEM examination, after $2 \mathrm{~h}$ drying at $37^{\circ} \mathrm{C}$, the dentin slices were mounted onto aluminum FEI stubs and 
subsequently coated with a thin layer of gold/palladium in a sputter coater. The specimens were viewed on the material surfaces and on dentin tubular longitudinal sections in a Quanta 200 scanning electron microscope (FEI) at a constant working distance. Original magnifications 5000×.

\section{Results}

\subsection{Cytotoxicity to human gingival fibroblasts}

The three materials were cytotoxic to gingival fibroblasts when they were tested undiluted. In order to have a better idea about the toxicity, additional dilutions of each material were tested. These revealed that Isodan ${ }^{\circledR}$ was the most cytotoxic with a very high toxicity even when diluted to 1:10. Duraphat ${ }^{\circledR}$ showed a significant decrease after a dilution to 1:2. The toxicity of Shellac F was intermediate with a significant decrease only after a dilution to 1:10 (Table 2).

The two-way ANOVA showed statistically significant differences among the three materials of both parameters studied: dilution $(p<0.0001)$ and material $(p=0.03)$. This means that cytotoxicity decreased with the medium dilution and that material toxicities were different. The Duncan test showed that Duraphat ${ }^{\circledR}$ was less cytotoxic than Isodan ${ }^{\circledR}$ and Shellac $F$ when tested undiluted or after a dilution to 1:2. Duraphat ${ }^{\circledR}$ and Shellac $F$ were less cytotoxic than Isodan ${ }^{\circledR}$ when tested at the 1:10 dilution. No difference was observed among the three materials when tested at the 1:100 dilution.

\subsection{Cytotoxicity to human pulp fibroblasts through dentin slice interposition}

The toxicity of the undiluted media was much lower than that on gingival fibroblasts. However, all three materials were toxic with the undiluted test media and at the dilution of 1:2. This toxicity decreased significantly from the dilution of 1:10 for all of the three materials (Table 3 ). The ANOVA showed that cytotoxicity decreased with dilution $(p<0.001)$ but no effect of the material was observed (ns). In other words, the three materials exhibited the same cytotoxicity which decreased with dilution.

Table 2 - Cytotoxicity of the three materials on human gingival fibroblasts

\begin{tabular}{lccc} 
Dilutions & Shellac F & Duraphat $^{\circledR}$ & Isodan $^{\circledR}$ \\
\hline Undiluted & $86(3) \mathrm{a}$ & $77(4) \mathrm{b}$ & $88(3) \mathrm{a}$ \\
$1 / 2$ & $85(3) \mathrm{a}$ & $14(13) \mathrm{b}$ & $87(3) \mathrm{a}$ \\
$1 / 10$ & $16(17) \mathrm{b}$ & $11(21) \mathrm{b}$ & $82(6) \mathrm{a}$ \\
$1 / 100$ & $2(20) \mathrm{a}$ & $10(22) \mathrm{a}$ & $0(20) \mathrm{a}$ \\
\hline
\end{tabular}

The ANOVA showed that the three materials were different $(p=0.03)$ and that cytotoxicity decreased with dilution $(p<0.0001)$.

According to Duncan test, the materials with the same letter, within the same dilution, were not statistically different. Results are expressed as mean of mortality percentage (S.D.).
Table 3 - Cytotoxicity of the three materials human pulp fibroblasts

\begin{tabular}{lrcr} 
Dilutions & Shellac F & Duraphat $^{\circledR}$ & Isodan $^{\circledR}$ \\
\hline Undiluted & $40(9)$ & $34(6)$ & $37(4)$ \\
$1 / 2$ & $35(9)$ & $25(10)$ & $30(6)$ \\
$1 / 10$ & $16(12)$ & $10(12)$ & $13(6)$ \\
$1 / 100$ & $0(17)$ & $0(14)$ & $0(10)$ \\
\hline
\end{tabular}

The ANOVA showed that cytotoxicity decreased with dilution $(p<0.001)$ but that no material was different from others (ns). Results are expressed as mean of mortality percentage (S.D.).

\subsection{Determination of hydraulic conductance}

All of the three materials resulted in a large decrease in hydraulic conductance of dentin ranging from $60 \pm 21$ (\%) with Isodan ${ }^{\circledR}$ to $76 \pm 28(\%)$ with Shellac F at $24 \mathrm{~h}$ and from $51 \pm 25$ (\%) with Shellac F to $77 \pm 23$ (\%) with Isodan ${ }^{\circledR}$ at 7 days after application (Table 4).

The ANOVA performed with the $24 \mathrm{~h}$ results showed that there was no statistical difference between the three materials $(p>0.05)$. On the other hand, according to the ANOVA performed with the 7 days results, there was a statistically significant difference among the three materials $(p=0.01)$. The Duncan test showed statistically significant differences among the groups. Isodan ${ }^{\circledR}$ reduced hydraulic conductance statistically more than Duraphat ${ }^{\circledR}$, which in turn was more effective than Shellac F.

\subsection{SEM examination}

At $24 \mathrm{~h}$, a rough and thick layer of material covering the dentin slices treated was observed with Shellac F (Fig. 1a). The layer covering with Duraphat ${ }^{\circledR}$ was composed of smaller particles (Fig. 1b). Isodan ${ }^{\circledR}$ created a transparent and thin layer that left most dentin tubules opened (Fig. 1c). During longitudinal section examination, many dentin tubules were plugged by the material with Shellac F as well as Duraphat ${ }^{\circledR}$ (Fig. 1a' and b') but not with Isodan ${ }^{\circledR}$ (Fig. 1c').

After 7 days, dentin surface observation demonstrated an adherent layer still covered almost all the surfaces treated

Table 4 - Percentage of hydraulic conductance decrease $24 \mathrm{~h}$ and 7 days after application of the three desensitizing agents

Material Hydraulic conductance Hydraulic conductance decrease $24 \mathrm{~h}$ after decrease 7 days after application (\%) application (\%)

\begin{tabular}{lll}
\hline Shellac F & $76(28)$ & $51(25)^{\mathrm{a}}$ \\
Duraphat $^{\circledR}$ & $67(23)$ & $67(29)^{\mathrm{b}}$ \\
Isodan $^{\circledR}$ & $60(21)$ & $77(23)^{\mathrm{c}}$
\end{tabular}

The $24 \mathrm{~h}$ ANOVA showed no difference among the three materials (ns). The 7 days ANOVA showed a statistically significant difference among the materials $(p=0.01)$. The groups with the different superscript letter are statistically different. The results are expressed as mean hydraulic conductance percentage decrease of the pretreatment value (S.D.). 

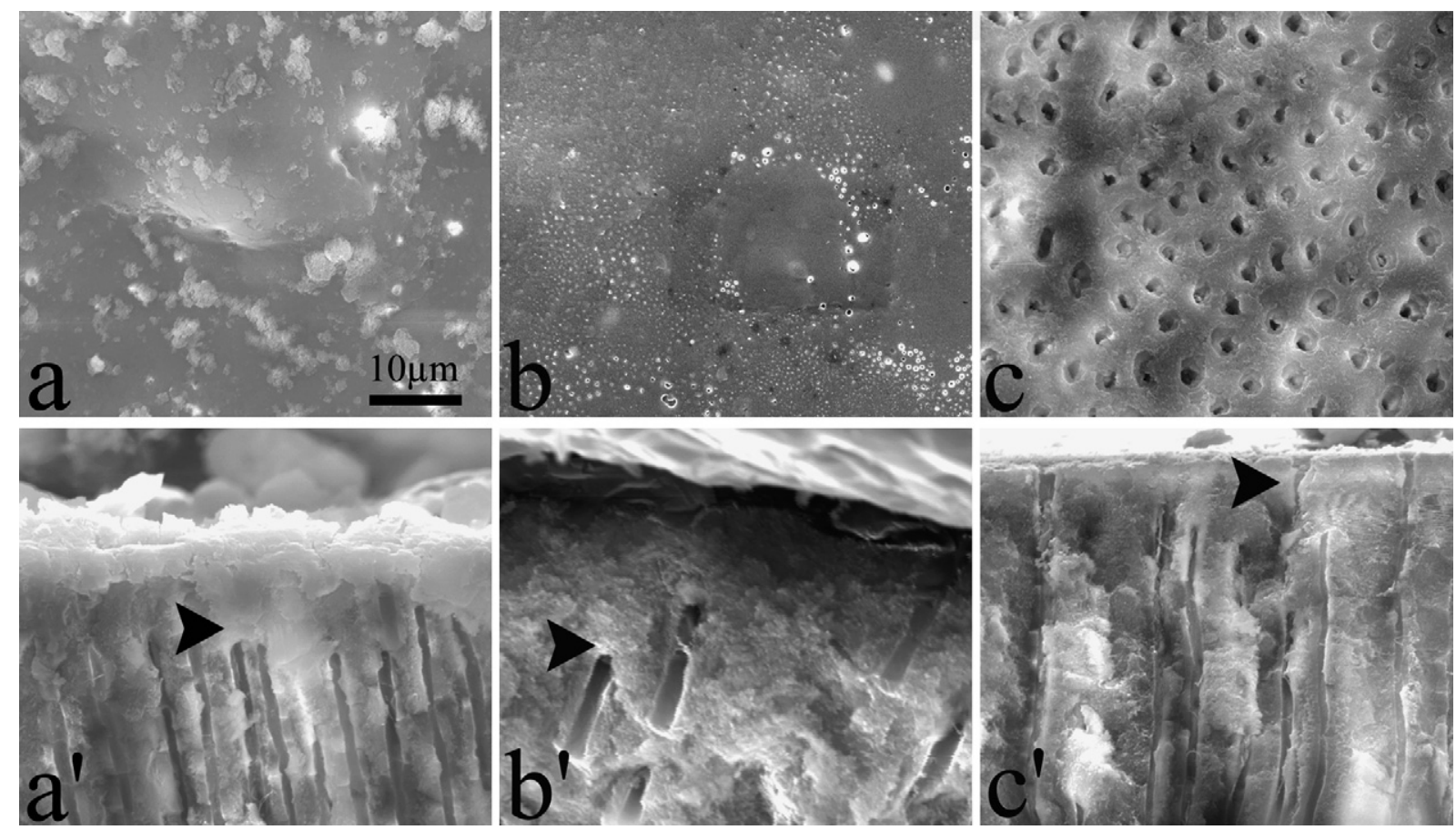

Fig. 1 - SEM $24 \mathrm{~h}$ after the materials application: Shellac $\mathrm{F}\left(\mathrm{a}\right.$ and $\left.\mathrm{a}^{\prime}\right)$, Duraphat ${ }^{\circledR}\left(\mathrm{b}\right.$ and $\left.\mathrm{b}^{\prime}\right)$ and Isodan ${ }^{\circledR}$ (c and $\left.c^{\prime}\right)$ on dentin surface $(a-c)$, and dentin tubular longitudinal sections $\left(a^{\prime}-c^{\prime}\right)$. Note the thickness of the tubular occlusion by a layer of material with Shellac F and Duraphat ${ }^{\circledR}$ (arrowheads $a^{\prime}$ and $b^{\prime}$ ) compared to Isodan ${ }^{\circledR}$ where some tubules were still opened and some others contained a loose material (arrowhead $c^{\prime}$ ). Original magnifications 5000x.
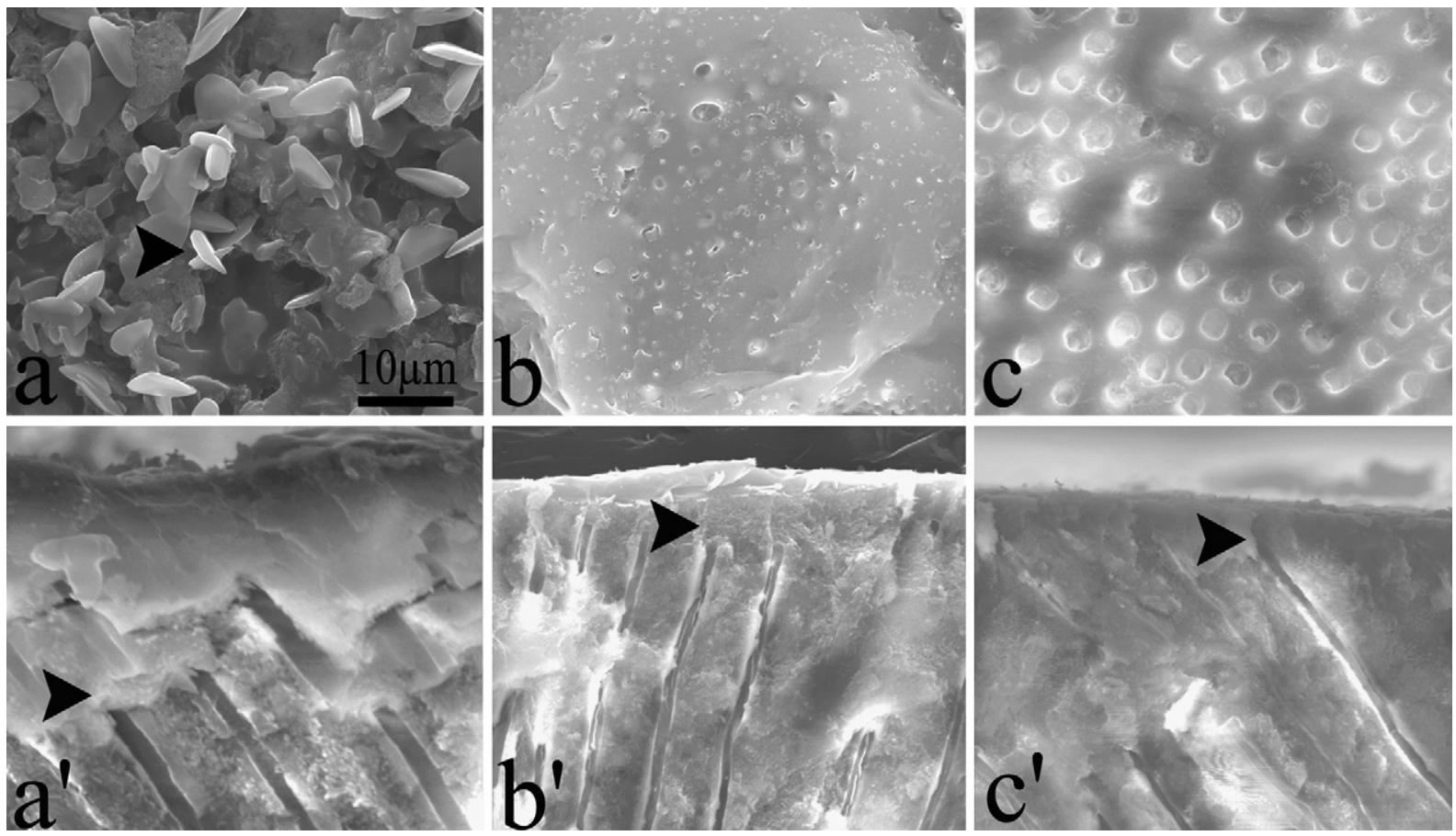

Fig. 2 - SEM 7 days after the materials application: Shellac F (a and $\left.a^{\prime}\right)$, Duraphat ${ }^{\circledR}\left(b\right.$ and $\left.b^{\prime}\right)$, and Isodan ${ }^{\circledR}\left(c\right.$ and $\left.c^{\prime}\right)$ on dentin surface $(a-c)$ and dentin tubular longitudinal sections $\left(a^{\prime}-c^{\prime}\right)$. Note the crystals on the Shellac $F$ specimens (arrowhead a); and note the tubular occlusions with Shellac $F$ and Duraphat ${ }^{\circledR}$ materials (arrowheads $a^{\prime}$ and $b^{\prime}$ ) compared to Isodan ${ }^{\circledR}$ (arrowhead $c^{\prime}$ ). Original magnifications 5000x. 
with Shellac F and Duraphat ${ }^{\circledR}$ (Fig. 2a and b). This was not the case with Isodan ${ }^{\circledR}$ (Fig. 2c). The layer of Shellac F was still covering the dentin surface with crystalline structures (Fig. 2a). No significant modification was observed on the longitudinal sections of dentin disks treated either with Shellac F, Duraphat ${ }^{\circledR}$ or Isodan ${ }^{\circledR}$ (Fig. 2a'- $\mathrm{c}^{\prime}$ ).

\section{Discussion}

This study evaluated the cytotoxicity and the efficiency as desensitizing agent of the experimental prototype fluoride varnish Shellac F. The new material was compared to a fluoride-containing gum lac designed for dentin hypersensitivity treatment (Duraphat ${ }^{\circledR}$ ) and another fluoride containing desensitizing agent (Isodan ${ }^{\circledR}$ ).

The cytotoxicity was evaluated on gingival fibroblasts and through a dentin slice interposition on pulp fibroblasts. This may simulate clinical conditions because these materials may be cytotoxic toward gingival cells in case of misapplication and toward the pulp cells by diffusion through dentin. When the media incubated with the materials were used to culture the gingival fibroblasts, Duraphat ${ }^{\circledR}$ was the least toxic of the three materials, followed by Shellac F which was less cytotoxic than Isodan ${ }^{\circledR}$. The relative high toxicity of Isodan ${ }^{\circledR}$ could be explained by its composition. Isodan ${ }^{\circledR}$ contains 2hydroxyethyl methacrylate (HEMA) which may be released from a resin-based material, move into the biophase, and act as toxic compound to the underlying tissues [24-27]. The cytotoxicity reported here toward the gingival fibroblasts has probably no clinical significance because saliva may dilute the material to such an extent that no side effect of Isodan ${ }^{\circledR}$ has been reported so far in the literature. When evaluating the cytotoxicity through dentin slice interposition, the three materials were also toxic to pulp fibroblasts. However, toxicity was lower than that found on gingival fibroblasts but no significant difference was found among the three materials (ns). This decrease may be explained by the buffering capacity of dentin [28]. Pulpal clearance was not simulated here and would certainly have lowered even more the recorded cytotoxicity. It can be concluded from this study that the cytotoxicity of these materials is mild and likely clinically irrelevant. Shellac F had a cytocompatibility which was comparable with the clinically used products and can be considered as adequate to dental application [29].

To evaluate the efficiency of Shellac $F$ in reducing dentin permeability, hydraulic conductance of human dentin slices was recorded using the Flodec device. This permits the comparison of the effects on the same dentin slice over time. Therefore, it increases the power of statistical analysis because each dentin slice is its own control. At $24 \mathrm{~h}$ after its application, Shellac $F$ was the most effective material with $76 \%$ of dentin permeability decrease, but this efficiency decreased to $51 \%$ at 7 days. Duraphat ${ }^{\circledR}$ showed a constant efficiency over time with a percentage of hydraulic conductance decrease of $67 \%$ after $24 \mathrm{~h}$ and 7 days. For Isodan ${ }^{\circledR}$, the percentage of hydraulic conductance decrease was $60 \%$ after $24 \mathrm{~h}$ and $77 \%$ after 7 days, which were not far from the results of a previous study [29]. Since the lowest effect of the desensitizing agents on hydraulic conductance was recorded with Shellac F at 7 days, one may question the duration of its effects. Therefore, only further clinical studies will allow us to know whether a $50 \%$ decrease in hydraulic conductance at 7 days is enough to obtain a long-lasting relief of dentin hypersensitivity pain. However, the values recorded here are in agreement with other studies performed on clinically satisfying desensitizing agents [29].

The SEM examination can help to elucidate the mechanism by which the material impacted dentin permeability more in depth. However, the need to maintain experimental conditions close to the in vivo situation is not possible with a conventional high vacuum SEM. Image interpretation is subjective even if some quantitative parameters can be recorded to better assess tubule occluding effects of selected desensitizing agents [30]. In addition, fracturing dentin disks to observe the longitudinal section may dislodge intratubular material making it difficult to consistently observe subsurface occlusion. That is why some authors find the functional measurements of dentin permeability more useful than SEM observations [31]. In addition to the hydraulic conductance recording, SEM examinations were used to have an insight on the mechanisms underlying the variation of dentin permeability. SEM examination of dentin surfaces at $24 \mathrm{~h}$ showed that, with Shellac F and Duraphat ${ }^{\circledR}$ a layer of material deposits completely masked the dentinal tubules. The longitudinal sections, showed the thickness of the layer deposited onto the dentin surface. Despite this layer, the hydraulic conductance was only reduced by $70 \%$. This may be due to the fact that the materials may be hydrophilic. The dentin surface treated with Isodan ${ }^{\circledR}$ did not show any modification of the dentin surface. There were several intratubular deposits but not always at the tubular openings, corroborating previous results [29]. At 7 days, the exposed dentin tubular area was not seen due to the presence of crystal deposits over the Shellac F surface. The composition of the globular deposits was not studied, but in longitudinal sections, tubular occlusions were still observed by the presence of a deposition layer of material. No difference was noticed between the $24 \mathrm{~h}$ and 7 days SEM views of dentin slices treated with Isodan ${ }^{\circledR}$.

The results have shown the efficiency of Shellac $F$ in reducing the dentin permeability and suggest that it may be safely used as an efficient desensitizing agent. This needs to be more deeply elucidated by follow-up clinical trials to explore not only the tubular occlusion effect but also different mechanisms such as the biochemical blocking of neural transmission or the development of natural desensitization following the temporary reduction in dentin permeability.

\section{Acknowledgements}

This work was undertaken at Laboratoire IMEB, Faculté d'Odontologie, Université de la Méditerranée, Marseille, France and was supported by institutional funding from French "Ministère de l'éducation nationale, de l'enseignement supérieur et de la recherche" and the Ministry of Education and Formation of Viet Nam.

We thank Mr. Allasia C, Centre de Microscopie Electronique, Faculté de Médecine, Université de la Méditerranée, for his help of the SEM investigation. 
relation to the clinical presentations. Contact Dermatitis 2006;55:216-8.

[1] Rees JS, Addy M. A cross-sectional study of dentin hypersensitivity. J Clin Periodontol 2002;29:997-1003.

[2] Gillam DG, Mordan NG, Newman HN. The dentin slice surface: a plausible model for dentin physiology and dentin sensitivity evaluation. Adv Dent Res 1997;11:487-501.

[3] Brännström M. Sensory mechanism in dentine editor. In: Anderson JD, editor. A hydrodynamic mechanism in the transmission of pain producing stimuli through the dentine. Oxford: Pergammon Press; 1963. p. 73-9.

[4] Brännström M. The surface of sensitive dentine. Odont Rev 1965;16:293-9.

[5] Ishikawa S. A clinico-histological study of the hypersensitivity of dentine. JJpn Stomatol Soc 1969;36:66-88.

[6] Absi EG, Addy M, Adams D. A study of the patency of dentinal tubules in sensitive and non sensitive cervical dentine. J Clin Periodontol 1987;14:280-4.

[7] Yoshiyama M, Masada J, Uchida A, Ishida H. Scanning electron microscopic characterization of sensitive us. insensitive human radicular dentin. J Dent Res 1989;68:1498-502.

[8] Yoshiyama M, Noiri Y, Ozaki K, Uchida A, Ishikawa Y, Ishida $\mathrm{H}$. Transmission electron microscopic characterization of hypersensitive human radicular dentin. J Dent Res 1990;69:1293-7.

[9] Dababneh RH, Khouri AT, Addy M. Dentin hypersensitivity an enigma? A review of terminology, mechanisms, aetiology and management. Br Dent J 1999;187:606.

[10] Orchardson R, Gillam DG. Managing dentin hypersensitivity. JADA 2006;137:990-8.

[11] Pamir T, Özyazici M, Baloğlu E, Önal B. The efficacy of three desensitizing agents in treatment of dentin hypersensitivity. J of Clin Pharm Ther 2005;30:73-6.

[12] Gaffar A. Treating hypersensitivity with fluoride varnish. Compend Contin Educ Dent 1999;20(Sp 1):27-33.

[13] Wulknitz P. Cleaning power and abrasivity of European toothpastes. Adv Dent Res 1997;11:576-9.

[14] Litonjua LA, Andreana S, Bush PJ, Tobias TS, Cohen RE. Wedged cervical lesions produced by toothbrushing. Am J Dent 2004;17:237-40.

[15] Hatton JF, Pashley DH, Shunk J, Stewart GP. In vitro and in vivo measurement of remaining dentin thickness. J Endod 1994;20:580-4.

[16] Gerzina TM, Hume WR. Diffusion of monomers from bonding resin-resin composite combinations through dentine in vitro. J Dent 1996;24:125-8.

[17] Ziad Khamaysi, Reuven Bergman, Sara Weltfriend. Positive patch test reactions to allergens of the dental series and the

[18] Luangtana-Anan M, Limmatvapirat S, Nunthanid J, Wanawongthai C, Chalongsuk R, Puttipipatkhachorn S. Effect of salt and plasticizers on stability of shellac film. J Agric Food Chem 2007;55:687-92.

[19] Smolinske SC. Handbook of Food Drug and Cosmetic Excipients. Boca Raton, FL: CRC Press; 1992.

[20] Limmatvapirat S, Limmatvapirat C, Luangtana-Anan M, Nunthanid J, Oguchi T, Tozuka Y, et al. Modification of physicochemical and mechanical properties of shellac by partial hydrolysis. Int J Pharm 2004:41-9.

[21] Hoang-Tu H, Huynh AL, Phan AH et al., Production and testing of a shellac based varnish for the prevention of dental caries. Final report of Research grant of the Vietnam Ministry of Health 1997 (in Vietnamese).

[22] Uehara A, Muramoto K, Imamura T, Nakayama K, Potempa J, Travis J, et al. Arginine-specific gingipains from Porphyromonas gingivalis stimulate production of hepatocyte growth factor (scatter factor) through protease-activated receptors in human gingival fibroblasts in culture. J Immunol 2005;175:6076-84.

[23] About I, Bottero MG, Denato P, Camps J, Franquin JC, Mitsiadis TA. Human Dentin Production in vitro. Exp Cell Res 2000;258:33-41.

[24] Kaga M, Noda M, Ferracane JL, Nakamura W, Oguchi H, Sano $\mathrm{H}$. The in vitro cytotoxicity of eluates from dentin bonding resins and their effect on tyrosine phosphorylation of L929 cells. Dent Mater 2001;17:333-9.

[25] Hum WR. Influence of dentin on the pulpward release of eugenol or acids from restorative materials. J Oral Rehabil 1994;21:469-73.

[26] Costa CAS, Vaerten MA, Edwards CA, Hanks CT. Cytotoxic effects of current dental adhesive systems on immortalized odontoblast cell line MDPC-23. Dent Mater 1999;15:434-41.

[27] Parajpe A, Bordador LCF, Wang M-Y, Hume WR, Jewett A. Resin monomer 2-hydroxyethyl methacrylate (HEMA) is a potent inducer of apoptotic cell death in human and mouse cells. J Dent Res 2005;84:172-7.

[28] Camps J, Pashley DH. Buffering action of human dentin in vitro. J Adhes Dent 2000;2:39-50.

[29] Camps J, About I, Van Meerbeek B, Franquin JC. Efficiency end cytotoxicity of resin-based desensitizing agents. Am J Dent 2002;15:300-4.

[30] Ahmed TR, Mordan NJ, Gilthorpe MS, Gillam DG. In vitro quantification of changes in human dentin parameters using SEM and digital analysis. J Oral Rehabil 2005;32:589-97.

[31] Zhang Y, Agee K, Pashley DH, Pashley EL. The effects of Pain-Free desensitizer on dentin permeability and tubule occlusion over time, in vitro. J Clin Periodontol 1998;25:884. 